Editorial

\title{
Can We Hide in Shadows When the Times are Dark?
}

\author{
Thorsten Quandt \\ Department of Communication, University of Münster, 48143 Münster, Germany; \\ E-Mail: thorsten.quandt@uni-muenster.de
}

Submitted: 17 January 2021 | Published: 3 February 2021

\begin{abstract}
The editorial discusses the relevance of analyzing some problematic aspects of online participation in consideration of events that happened during the preparation of this thematic issue. It critically challenges the eponymous 'dark participation' concept and its reception in the field, and calls for a deeper exploration of epistemological questions - questions that may be uneasy and difficult to answer, as they also refer to the issue of balance and scientific positioning in the face of threats to public communication and democratic ideals.
\end{abstract}

\section{Keywords}

dark participation; disinformation; duality; epistemology; participatory journalism; public communication; online communication

\section{Issue}

This editorial is part of the issue "Dark Participation in Online Communication: The World of the Wicked Web" edited by Thorsten Quandt (University of Münster, Germany).

(C) 2021 by the author; licensee Cogitatio (Lisbon, Portugal). This article is licensed under a Creative Commons Attribution 4.0 International License (CC BY).

\section{The Season of Light, the Season of Darkness}

It was the best of times, it was the worst of times, it was the age of wisdom, it was the age of foolishness, it was the epoch of belief, it was the epoch of incredulity, it was the season of Light, it was the season of Darkness. (Dickens, 1859, p. 1)

The famous opening paragraph of Dickens' A Tale of Two Cities masterfully describes the major conflicts and extremes of a chaotic time of social and political upheavals. Set in the years leading to the French revolution, the historical novel is referring to a specific period and location (to be more precise, two specific locations: the eponymous two cities London and Paris)-but the opening paragraph has gained a life of its own in public, (pop) culture and science. I am not a native speaker, but it always struck me with awe: It's an ingenious way of expressing the duality of revolutionary times, and in some ways, also of how some of our current times feel like.

Dickens' opening paragraph transcends the specifics of the novel's plot and localization, and that is proba- bly why so many people since the original publication in 1859 could connect to its deeper meaning, especially so if they found themselves in periods of profound social change. Indeed, his magnificent lines sound more current than ever, and they also resonate with this thematic issue's topic-especially as they literally refer to the duality of light and darkness as two opposing positions and potentials.

A figurative understanding of light and dark, referring to a larger duality of the social, is a seed concept of this current issue. When being approached by Media and Communication to serve as the editor of a thematic issue, I had just published an article in said journal on "dark participation" (Quandt, 2018), focusing on the "bleak flip side" (p. 18) of citizen participation in online environments, including phenomena like trolling, bullying, strategic disinformation and hate campaigns. Based on the strong, and sometimes even quite emotional reactions to this piece (which are certainly not the standard for a publication in a scientific journal), its core topic looked like a perfect candidate for deeper exploration. Little did I know what would happen in the short time between the call for papers, the subsequent review 
process of the amazing pieces the journal received, and the release of the issue-and how this would make both the topic (and the introductory Dickens quote) more current than ever.

In barely 18 months, the world witnessed the outbreak and rapid development of a pandemic, paralleled by a confusing cacophony of voices, conspiracy theories and disinformation regarding the Coronavirus, some of it originating from dubious sources on the web and dark participation in online forums. Early on in the crisis, the WHO labeled this an 'infodemic' (WHO, 2020)-a highly contested (but yet popular) term to describe the social and communicative situation in the pandemic. Naturally, the critics are correct: As a start, it would need to be called a 'disinfodemic,' if the core problem is intentional falsehoods and not just an exponential growth of information in a short time-and there are other limitations of this concept that cannot be discussed in a brief editorial. Yet, it still underlines the timeliness of this issue's core ideas, which seemed to gain even more urgency in the Coronavirus crisis.

Shortly before release date, the world's longeststanding democracy - the United States of Americawere shaken by pictures of a mob storming the Capitol, incited by a president who had lost the election, but did not accept the results of the election and called it rigged on multiple occasions (without presenting substantial proof for these claims). For that infamously 'twittering' president, traditional media were primarily 'fake news,' and many of his supporters organized themselves via social media and online platforms-the most radical ones just trusting their own sources and stirring up themselves in a rather hermetic information environment. While communication studies has rightfully questioned the existence of "filter bubbles" in general (Bruns, 2019), it became apparent that there are related issues on the extreme edges of an increasingly polarized society, where opinion formation is (self-)organized in radical pockets of a rather 'wicked' web. Indeed, public observers identified some forms of 'dark participation' in online environments as a danger to democracies, and numerous politicians around the world called for action against populism, hate and disinformation.

These incisive developments call for a short moment of reflection regarding the conceptual core of this thematic issue, its changing context and resulting epistemological questions. Therefore, this editorial slightly deviates from the expectation of giving an overview of the enclosed articles. Luckily, my colleague Oscar Westlundeditor of the journal Digital Journalism-was asked to comment on the thematic issue, and he does a much better job at an introduction than me here (Westlund, 2021). Reading his commentary before working through the issue is highly recommend, and then re-reading it after that procedure as well. Further, the current president of the International Communication Association Claes de Vreese adds some crucial contextual thoughts, putting some of the arguments in this thematic issue in (disciplinary) perspective (de Vreese, 2021). Reading his commentary as a concluding remark will certainly widen the scope of how the issues at stake can be discussed.

\section{Darkness, Debates and Discipline}

As mentioned above, the idea for this thematic issue had its origin in an earlier, quite personal exploration of dark participation in online environments, published in this very journal roughly two years ago. Like this editorial, I chose to partially deviate from a traditional article format there. If you haven't read it and still plan to do sothen please stop reading exactly here $\rightarrow\{\leftarrow$, as the following will include 'spoilers'!

The piece itself was, on the surface, an exploration of the concept of 'dark participation,' which was depicted as a counter-concept to a 'naïve,' abundantly positive and 'pure' concept of user participation discussed in communication studies and journalism roughly around the turn of the millennium and the subsequent decade. The 'dark participation' concept was developed in a systematic, yet intentionally generic way in the middle section of the piece. However, this systematic discussion of dark participation was also meant as a device to lead the reader astray: The plan was to get the reader nodding her or his head and agreeing with the argument. The reader should fully embrace the focus on dark participation as an innovative and convincing concept. Then, in the last third of the article, it was revealed that such a one-sided debate of the 'dark' side would be equally misguided as the overly optimistic and normatively narrow expectations regarding participation, and that some crucial and balancing counter-arguments were left out on purpose to get her or him agreeing with the intended position. So the article was actually a call for balance in the discussion, despite its title and core concept: Just focusing on dysfunctional effects and being fascinated by the doom and gloom of the dark side would be as wrong as naïvely expecting every user in online environments to be a heroic, liberal savior of democracy. Metaphorically speaking, the pitch black of 'dark participation' in the piece was poured into the crystal white of some earlier approaches to end up with a more fitting grey.

As noted above, the article lead to some surprisingly emotional, even visceral reactions, which are uncommon for a scientific journal article: Some readers loved it, and some really hated it. And in both groups, there were people who just referred to the dark participation concept itself without the proper 'balancing' contextualizationmaybe overlooking the mirror trick this article really is. Now I mention this article and its history not for selfreflection, but to point out the issues of doing research on participation in general, and how personal and emotional it can be: This is not an 'empty' concept by definition, as the participation in public communication and social processes logically refers to democratic idealsand therefore ideas that may be close to our heart. It can be theoretically argued that citizen participation always 
entails an ethical component, therefore something like 'dark participation' does not exist or is a "perversion" (Carpentier, Melo, \& Ribeiro, 2019) of participation-and indeed, the 'pure' form of citizen participation is a shimmering star in the sky that may be needed as guidance for our actions. On the other hand, there is ample of empirical proof that there are grave issues with some forms of participation in online environments-and we as social scientists cannot ignore the fact that parts of the political elite and public in many countries regard some of these a danger to society (and even call for measures to restrict dark participation).

In that sense, a discussion of such phenomena leads to difficult epistemological questions, and calls for a reflection on our positioning and perspective as individual scholars and our discipline(s) at large.

\section{Out of the Grey Zone, Back into the Light?}

Following the above argument, can we as scientists stay in the secure space of the ivory tower and observe these issues from afar, with the impartial gaze of a neutral observer, painting the world in a diffuse grey? Or do we even stand on top of it, and observe through a normative lens with conceptual nobility, far above the lowlands of confusing empirical contradictions? And all of this while we receive alarming evidence of concepts like participation being turned into a dark counter-image of what we hoped they would be?

As noted above, the initial piece on dark participation argued for balance-based on my personal perception of a dominant one-sidedness both in the early debate on participation and its much darker counterpart as of recently. However, such a call for balance may also lead to a situation where scientists hide in a hazy and shapeless 'grey zone,' where no position is taken, everything appears value free-and everything looks similar. Given the events that happened during the production of this thematic issue, and based on the findings and approaches assembled here, I have some nagging doubts. Figuratively speaking: Can we as scientists hide in shadows when the times are getting darker and darkerand won't the safe grey zone disappear with the fading light? Maybe we cannot be fully neutral here, as open science itself is also part of open debates and open societies? And therefore, shouldn't we have a vital interest in their success?

Naturally, this refers to well-known epistemological questions of social sciences and the dispute between normative positions and a (arguably) 'value free' criticalrationalist position, and between neutral and activist research. While some of these questions have been discussed in great depth in other fields, and while they were always somewhat present in communication studies, I feel that they need to be discussed in a more substantive way, given the current challenges we observe in online communication and the social alike. It is no coincidence that difficult times of social change often breed epistemological questions and paradigmatic changes in science as well-as change and the related anomalies reveal fractures in existing paradigms. The events we saw unfold during the preparation of the thematic issue may be partially cause and effect of such change. Some of it is related to the evolution of online communication and the transformation of society in an increasingly 'digitized' world, where information flows do not adhere to the logics of traditional media and journalism. Dark participation (or whatever label you prefer) is certainly not its sole cause, but part of this.

In this short editorial, I could only hint at these deeper, epistemological issues that parallel the fine pieces of research in this thematic issue. Naturally, there is notable variance here: The authors come from different world regions-Europe, Asia and the United Statesthey analyse multiple forms of 'dark participation' in online communication, and they favor various empirical and theoretical approaches. However, they are united by their deep interest in the given phenomena, often driven by an implicit or explicit goal: exploring dark participation and delineating it from its light counterpart. And by doing so, they may be helping in saving citizen participation from the destructive 'doom and gloom' that seems to be so pervasive these days. This may also be an answer to my concerns that an occupation with the dark side may result in a diffuse gray-researching dark participation in such a way may contribute to a better understanding of other forms of participation as well, and therefore help in identifying factors that protect these from being dragged into the dark. So instead of ending up in a diffuse grey zone, such research may result in a much sharper contrast between light and dark.

The introductory quote from Dickens' A Tale of Two Cities brilliantly expresses this duality where the light and dark coexist in all their variety. Applied to the many negative observations our field has recently made in relation to forms of dark participation and their dangers to society, this also holds a hopeful promise: that if we observe chaos and foolishness in democratic crisis, then there is also the potential for stability, elegance and wisdom.

\section{Acknowledgments}

I would like to thank Oscar Westlund for his thoughtful comments that helped to further develop and refine the editorial.

\section{Conflict of Interests}

The author declares no conflict of interest.

\section{References}

Bruns, A. (2019). Are filter bubbles real? Cambridge: Polity.

Carpentier, N., Melo, A., \& Ribeiro, F. (2019). Rescuing participation: A critique on the dark participa- 
tion concept. Communicação e Sociedade, 36, 17-35. Retrieved from https://journals.openedition.org/cs/ 1284

de Vreese, C. (2021). Beyond the darkness: Research on participation in online media and discourse. Media and Communication, 9(1), 215-216.

Dickens, C. (1859). A tale of two cities. London: Chapman $\&$ Hall.

Quandt, T. (2018). Dark participation. Media and Communication, 6(4), 36-48.
Westlund, O. (2021). Advancing research into dark participation. Media and Communication, 9(1), 209-214.

WHO. (2020). Novel Coronavirus (2019-nCov) (Situation report No. 13). Geneva: WHO. Retrieved from https://www.who.int/docs/default-source/ coronaviruse/situation-reports/20200202-sitrep13-ncov-v3.pdf

\section{About the Author}

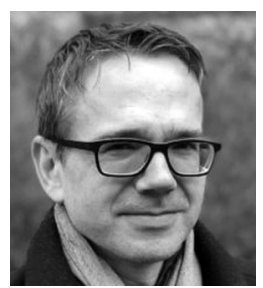

Thorsten Quandt is a Professor of Online Communication at the University of Münster, Germany. His research fields include online communication, digital games and (online) journalism. Quandt is particularly interested in the societal changes connected to the Internet and new media, and the question of how human beings have evolved in sync with these changes. His earlier works on participatory journalism and online newsroom production have been widely cited in the field of (digital) journalism research. 